\title{
The effect of instrument lubricant on the diametral tensile strength and water uptake of posterior composite restorative material
}

\author{
Mr Jaymit Patel a,* \\ Miss Clare Granger ${ }^{a}$ \\ Dr Sandra Parker ${ }^{\text {a }}$ \\ Dr Mangala Patel a
}

${ }^{\text {a }}$ Barts \& the London School of Medicine and Dentistry

Dental Physical Sciences, Institute of Dentistry

Francis Bancroft Building

Queen Mary, University of London

Mile End Road

London E1 4NS

United Kingdom

${ }^{*}$ Corresponding author:

Tel.; +44 7523914629

Email address; jaymit.patel@nhs.net 


\section{$\underline{\text { Abstract }}$}

\section{Objectives}

This in-vitro study investigated the effect of 'instrument lubricants' used during placement of composite restorative material, on the diametral tensile strength (DTS) and water uptake of composite specimens.

\section{Methods}

300 posterior composite cylindrical specimens were manufactured: 60 with each instrument lubricant (ethanol, 3-step, 2-step and 1-step 'bonding agent') and 60 with no lubricant (controls). Each set of 60 specimens was evenly allocated to one of the following test groups ( $\mathrm{n}=100 /$ group): Group 1 - tested for DTS immediately after manufacture; Groups 2 and 3 - tested for DTS after immersion in phosphate-buffered saline (PBS) for 1 and 12-weeks respectively, using a Universal Instron machine. Water uptake was assessed gravimetrically. Data were statistically analysed with two-way ANOVA and Tukey's post hoc test $(\alpha=0.05)$.

\section{Results}

The mean DTS and percentage weight change of composite specimens ranged between 32.49-53.14 MPa and $0.51-1.36 \%$ and varied with lubricant used and time incubated in PBS.

All control groups exhibited significantly higher DTS (MPa) (groups 1-3: 53.17 $\pm 1.78 ; 50.64 \pm 1.85$;

$45.17 \pm 1.77$ ) and lower percentage weight change (groups $2-3: 0.51 \pm 0.03 ; 0.61 \pm 0.01$ ) than specimens placed with an instrument lubricant, with significant differences between certain lubricant groups.

\section{Significance}

The use of instrument lubricants to aid composite placement is widespread to overcome difficulties with handling, however data obtained identify that lubricant use may adversely affect both DTS and water uptake. Thus, discontinuing or limiting the use of instrument lubricants, and if necessary using the 'bonding agent' from a 3-step adhesive system is recommended, as results suggest this has the least deleterious effect upon material properties. 


\section{Introduction}

Dental composite materials are widely used in restorative dentistry with an increasing popularity due to a decline in amalgam use and comparative advantages, such as pleasing aesthetic properties and preservation of tooth tissue [1]. However, despite their popularity, dental composite materials also possess numerous disadvantages, one of which relates to difficulty in handling during placement [2]. Indeed, clinicians widely report adherence of the material to the application instrument and 'pull-back' during insertion and condensation [2-4]. There have been many techniques suggested to overcome this handling challenge, including the development of plastic coated and titanium nitride instruments, instrument wetting resins [5] and the use of various 'lubricants' to coat instruments [3,4,6].

Whilst the difficulty of dental composite placement may be ameliorated by the use of an instrument lubricant, this technique should not contaminate or interfere with the setting, chemical or physical properties of the material. Previous research has clearly identified numerous contaminants during placement, such as: blood; saliva; astringents; haemostatic agents; dentine desensitisers and even powder from latex gloves, which can negatively impact upon material properties [7-9]. As such, although the use of instrument lubricants may improve ease of placement, it may be questioned: in search of improved handling, does a clinician unwittingly 'modify' or 'contaminate' the material by incorporating instrument lubricant into the polymerised composite, and thus affect its material properties?

There is a dearth of research evidence to demonstrate the impact of instrument lubricant use. Previous studies $[3,4,10]$ have investigated the effect of various bonding agent lubricants on the strength of dental composite material, however the methods used to construct specimens differed greatly from those used in the clinical environment, data remain contradictory and none investigated the use of newer $7^{\text {th }}$ generation self-etch bonding systems.

Furthermore, there has been no definitive research to date investigating the possible effects of instrument lubricant use on water uptake. Composite materials in the oral cavity undergo interaction with saliva [1115], however none of the previous studies subjected their composite specimens to an immersion period to 
simulate such an environment. The inclusion of additional resin matrix from use of a lubricant may increase water uptake and result in increased hydrolytic degradation and have significant deleterious clinical consequences [16-19].

\subsection{Study aims and hypothesis}

The present study assesses the impact of a range of instrument lubricants including a $7^{\text {th }}$ generation one-step self-etchant adhesive system. It also employs more clinically relevant composite placement methods, in order to address limitations in previous methodologies. In addition, the possible effects of instrument lubricant on the water uptake properties of composites are also investigated. Moreover, a longitudinal approach, involving a 1-week and 12-week immersion period, to simulate the oral cavity environment is utilised. Thus, the formulated aim for the present study was to evaluate whether the use of various 'instrument lubricants' during composite placement affects the diametral tensile strength and water uptake of posterior dental composite material. The null hypothesis tested was that 'instrument lubricants' do not affect the diametral tensile strength or water uptake of posterior hybrid dental composite restorative material.

\section{Materials and Method}

300 hybrid posterior composite cylinder specimens (Solitaire 2, Heraeus Kulzer, Frankfurt, Germany) in shade A1 were prepared in polytetrafluoroethylene (PTFE) moulds, each measuring $5 \mathrm{~mm}$ in diameter and $8 \mathrm{~mm}$ in depth (comprising 4 x $2 \mathrm{~mm}$ increments). Four instrument lubricants were selected: ethanol; 3-step adhesive system (Kerr Optibond, use of adhesive bottle only); 2-step adhesive system (Kerr Solo-Plus, use of total-etch bottle only) and 1-step adhesive system (Kerr All-In-One, self-etch bottle). Please see Table 1 for base components of the adhesive systems used. Bonding systems were brand standardised (Kerr UK Ltd, Peterborough, UK) to eliminate the possibility of inter-brand variability. 60 cylinders were prepared with each of the four selected instrument lubricants and 60 cylinders were prepared as a control group without the use of instrument lubricant. 


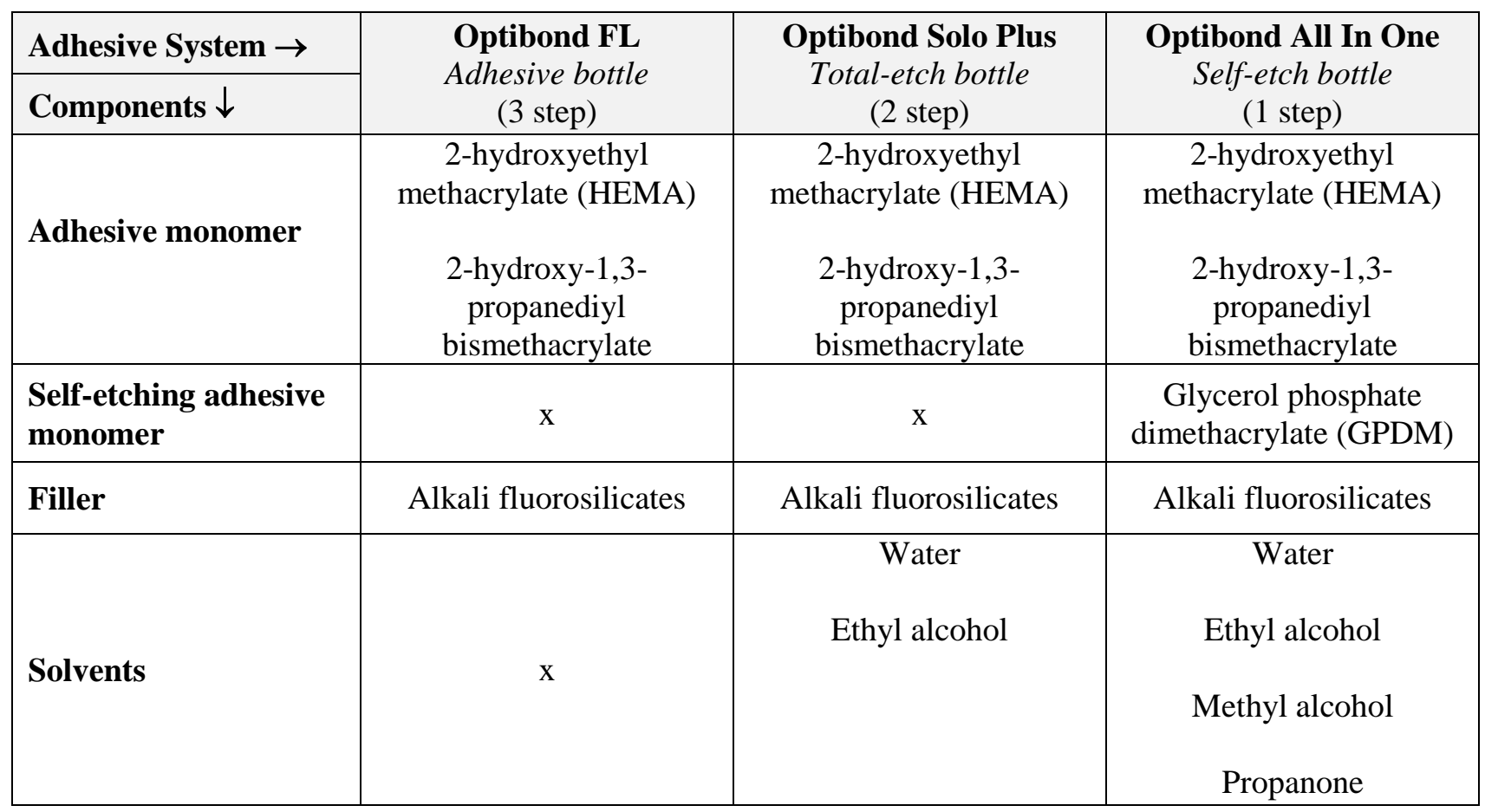

Table 1: Base components of the adhesive systems used as instrument lubricants [20-23]

Protocol planning included pilot studies, power calculations for number of specimens required and control of specimen size with dimension/weight measures. All specimens were prepared by 2 operators, with both trained and calibrated for their prospective task. Operator 1 placed the composite material and operator 2 light polymerised the cylinders. This protocol was adopted to eliminate inter-operator variability/error and increase reliability.

Operator 1 placed each $2 \mathrm{~mm}$ layer of composite with a stainless steel plugger. Within the control group, the composite was placed and contoured with a 'non-lubricated' plugger. For each of the four experimental lubricant groups, the plugger was dipped into each respective lubricant for 1 second (up to a $3 \mathrm{~mm}$ marked line on the instrument) and left to drip/drain for 2 seconds prior to use. No mixing of the adhesive lubricants was required prior to use, as only the (single component) adhesive bottle of the 3 -step, the total-etch bottle of the 2-step and self-etch 1-step bottle were utilised.

Operator 2 polymerised each incremental layer for 40 seconds with a halogen light cure lamp (Elipar, 3M ESPE, Minnesota, USA). Each composite layer was $2 \mathrm{~mm}$ in height, to allow for optimal polymerisation 
[24]. A glass slab was placed beneath the mould to support material during placement and above on the final increment, to prevent formation of an oxygen-inhibition layer. The light curing unit was held as close to the specimen as possible and cured at a minimum threshold intensity, as per the manufacturer's instructions. The output of the halogen lamp was calibrated after completion of every 20 cylinders using a handheld lightmeter and the intensity was maintained above $450 \mathrm{~mW} / \mathrm{cm}^{2}$ to ensure optimal polymerisation [24] (range $\left.450 \mathrm{~mW} / \mathrm{cm}^{2}-550 \mathrm{~mW} / \mathrm{cm}^{2}\right)$.

Following light polymerisation, the specimen cylinders were removed from the PTFE moulds and weighed on an electrical analytical balance (Model SI-403, Denver Instrument, Colorado, USA). Within each lubricant group, specimens were then randomly separated into three experimental groups: '0week/immediate', '1-week' and '12-week'. The 1-week and 12-week specimens were subject to longitudinal analysis following storage in phosphate buffered saline (PBS). PBS was used to maintain a physiologic environment similar to saliva [25]. For the '1-week' and '12-week' analyses each specimen was placed separately into a small glass storage bottle (with a sealed, stoppered lid) containing 10ml of PBS and were then stored in an incubator at $37^{\circ} \mathrm{C}$, to replicate the temperature of the oral cavity. 100 specimens were incubated for 1 week and another 100 incubated for 12 weeks. Following storage for each time period, the specimens were removed with tweezers from the individual storage bottles and allowed to drip/drain on a rack for 1 minute to remove excess PBS, prior to water uptake and strength testing.

Water uptake was assessed gravimetrically, by weighing the specimens at the time of manufacture and again after immersion in the PBS, on an electronic analytical balance. For each specimen, the percentage weight change over time was calculated.

The cylinder specimens were tested for DTS at all three time-points on a Universal Testing Machine (Model HK5S, Instron Ltd, High Wycombe, UK), with their long axis perpendicular to the applied compressive load, with a $5 \mathrm{KN}$ load cell at a constant crosshead speed of $10 \mathrm{~mm} / \mathrm{min}$, until the point of failure (machine set to peak hold). This compressive test identified fracture load (recorded in Newtons) and the DTS was calculated from this (in MPa) utilising the following formula [26]: 


$$
\begin{gathered}
\text { DTS }=\mathbf{2 F} / \boldsymbol{\pi d h} \\
\text { where: } \\
\mathrm{d}=\text { specimen diameter }(5 \mathrm{~mm}) \\
\mathrm{h}-\text { specimen height }(8 \mathrm{~mm}) \\
\pi=3.1416 .
\end{gathered}
$$

Diametral tensile strength was used as an indicator of mechanical strength to the point of fracture, as it closely replicates forces placed on restorative material in a posterior tooth in the oral cavity $[27,28]$. The data obtained for both water uptake and DTS assessments were analysed with descriptive statistics, parametric analysis of variance (two-way ANOVA) and Tukey's post hoc tests using the IBM SPSS statistics package. 


\section{Results}

\subsection{Diametral Tensile Strength}

The mean DTS values and standard deviations for all specimen groups are summarised in Table 2, along with levels of significance (with no significant differences between groups with the same letters).

\begin{tabular}{|c|c|c|c|c|}
\hline $\begin{array}{c}\text { Immersion } \\
\text { Time }\end{array}$ & $\begin{array}{c}\text { Lubricant } \\
\text { Group }\end{array}$ & $\begin{array}{c}\text { Mean DTS / } \\
\text { MPa }\end{array}$ & $\begin{array}{c}\text { Std. Deviation / } \\
\text { MPa }\end{array}$ & $\begin{array}{l}\text { Significance } \\
\text { group }\end{array}$ \\
\hline \multirow{5}{*}{0 Week } & Control & 53.1 & 1.8 & \\
\hline & 1 Step & 41.5 & 2.4 & $a$ \\
\hline & 2 Step & 44.1 & 1.6 & $a, b$ \\
\hline & 3 Step & 47.2 & 1.7 & $b$ \\
\hline & Ethanol & 40.6 & 1.4 & $a$ \\
\hline \multirow{5}{*}{1 Week } & Control & 50.6 & 1.9 & \\
\hline & 1 Step & 40.9 & 2.4 & $c, e$ \\
\hline & 2 Step & 42.9 & 1.8 & $c, d$ \\
\hline & 3 Step & 45.0 & 1.7 & $d$ \\
\hline & Ethanol & 37.7 & 1.9 & $e$ \\
\hline \multirow{5}{*}{12 Week } & Control & 45.2 & 1.8 & \\
\hline & 1 Step & 32.5 & 1.8 & $f$ \\
\hline & 2 Step & 34.4 & 1.7 & $f, g$ \\
\hline & 3 Step & 39.7 & 1.9 & $h$ \\
\hline & Ethanol & 37.2 & 1.9 & $g, h$ \\
\hline
\end{tabular}

Table 2: Mean diametral tensile strength (MPa) and standard deviations for the control and instrument lubricant groups, across the three time periods. Specimen groups sharing same letters for significance were not statistically different at $\mathrm{P}<0.05$. 
These data identified a statistically significant difference in DTS between control composite specimens produced with no instrument lubricant and those produced with all 4 of the instrument lubricants tested $(\mathrm{p}<0.05)$. At all temporal points the control specimens exhibited a significantly higher DTS than all those specimens placed with the use of a lubricant $(\mathrm{p}<0.05)$. There was a gradual reduction in the DTS of all composite specimen groups over the observed time periods.

There was a statistically significant difference in DTS between the specimens prepared with 3-step and 1step bond lubricants at all time-points tested $(\mathrm{p}<0.05)$ and between 3-step and 2-step bond lubricant use at the 12 -week time point $(\mathrm{p}<0.05)$. However, at no time-point was there a statistically significant difference between the DTS of composite specimens produced with 2-step and 1-step bond lubricants ( $>0.05$ ). Furthermore, analysis using two-way ANOVA identified a statistically significant interaction between instrument lubricant and time for DTS $(\mathrm{p}<0.05)$. 


\subsection{Water uptake}

Table 3 summarises mean percentage weight change and standard deviations for the control and each lubricant group, across the two time periods of PBS immersion, along with levels of significance (with no significant differences between groups with the same letters).

\begin{tabular}{|c|c|c|c|c|}
\hline $\begin{array}{l}\text { Immersion } \\
\text { Time }\end{array}$ & $\begin{array}{l}\text { Instrument } \\
\text { Lubricant }\end{array}$ & $\begin{array}{l}\text { Mean \% } \\
\text { weight change }\end{array}$ & Std. Deviation & $\begin{array}{l}\text { Significance } \\
\text { group }\end{array}$ \\
\hline \multirow{5}{*}{1 Week } & Control & 0.506 & 0.025 & \\
\hline & 1 Step & 1.251 & 0.079 & $a, b$ \\
\hline & 2 Step & 1.314 & 0.118 & $a, c$ \\
\hline & 3 Step & 1.301 & 0.045 & $b, c$ \\
\hline & Ethanol & 0.933 & 0.070 & \\
\hline \multirow{5}{*}{12 Week } & Control & 0.614 & 0.009 & \\
\hline & 1 Step & 1.295 & 0.054 & $d, e$ \\
\hline & 2 Step & 1.358 & 0.057 & $d, f$ \\
\hline & 3 Step & 1.343 & 0.066 & $e, f$ \\
\hline & Ethanol & 0.987 & 0.068 & \\
\hline
\end{tabular}

Table 3: Mean percentage weight change and standard deviations for the control and each lubricant group, across the two time periods of water immersion. Specimen groups sharing the same letters for significance were not statistically different at $\mathrm{P}<0.05$.

Analysis identified statistically significant differences $(p<0.05)$ in the percentage weight change between the control and lubricant groups, for both the 1-week and 12-week immersion periods. Tukey's post-hoc tests identified:

- Statistically significant differences in water uptake $(\mathrm{p}<0.05)$ between the control group and each of the 4 instrument lubricant groups.

- Statistically significant differences in water uptake $(\mathrm{p}<0.05)$ between each of the 3 bonding agent groups (3-step, 2-step \& 1-step bonding agents) and the ethanol lubricant group. 
- No statistically significant difference ( $p>0.05)$ in water uptake between the 3 different bonding agent systems used as instrument lubricants.

Data identified that composite specimens placed with any of the bonding agents as an instrument lubricant demonstrated a higher percentage weight change. Composites placed with ethanol as an instrument lubricant showed significantly more weight change than the control group, but significantly less than those placed with bonding agent lubricants $(\mathrm{p}<0.05)$. Composite specimens placed using 1 -step bonding system as an instrument lubricant had a lower percentage weight change than 2-step and 3-step lubricant specimens, however this difference was not statistically significant. Whilst analysis identified a statistically significant difference for water uptake in different lubricant and time groups, a two-way ANOVA did not identify a statistically significant interaction between lubricant and time.

\section{Discussion}

\section{1: Diametral Tensile Strength}

All composite specimens exhibited the highest DTS immediately following placement, with a reduction over time following immersion in PBS. It is proposed that this reduction in DTS reduces to a baseline level, as suggested in previous studies [29-31], although further longitudinal time intervals would need to be assessed to confirm this.

DTS for specimens ranged from 32.49 to $53.14 \mathrm{MPa}$. DTS values for control specimens were concordant with accepted values for composite restorative material from previous research literature [26,32]. All composite specimens placed with each of the four instrument lubricants showed significantly lower DTS compared to the control specimens produced without instrument lubricant, both immediately following placement and after an immersion period in PBS. This research finding does not support the null hypothesis.

Further to previous research, the results obtained from the present study enabled assessment and comparison of 3 different adhesive systems, including the newer $7^{\text {th }}$ generation all-in-one system. Results demonstrated that at 'immediate' and '1-week' assessments there was a statistically significant difference in DTS between 
those specimens produced with the use of bonding agent lubricant from the 3-step system, compared to the 1-step system. However, after a 12-week immersion period in PBS there was a significant difference between the DTS of the 3-step compared to both the 1-step and the 2-step specimens. Interestingly, there was no significant difference in DTS at any timepoint between the use of 1-step and 2-step bonding solutions used as instrument lubricants, possibly as both contained similar components such as 2-hydroxyethyl methacrylate, 2-hydroxy-1,3-propanediyl bismethacrylate, water, ethanol (Table 1). This suggests that some of the components in both the 2-step (total etch) and 1-step (self-etch) adhesive systems, when used as an instrument lubricant, may act as a contaminant and result in poorer physical properties of composite restorations.

The rate at which DTS reduced over time was similar for all specimens, except for those produced with an ethanol lubricant, where the initial reduction in strength (after 1-week immersion) was greater, followed by little reduction in strength after 12-week immersion in PBS. This may be due to ethanol leaching out more rapidly from the resin matrix compared to the larger unfilled and unreacted monomers within adhesive lubricants.

The specimens produced with ethanol as an instrument lubricant had a lower DTS compared to those in the control and 3-step lubricant groups, possibly due to the destruction of the oxygen inhibition layer between increments. The loss of this layer may account for the unusual "banding" noted in these specimens, where white opacities were visible, possibly representing poor interphase cohesion (see figure 1) [31]. This observation was also reported by Tjan and Glancy [10], however they did not propose a mechanism for this presentation. They observed that composite specimens frequently fractured at the interface between opaque and non-opaque segments, suggesting that the cohesive bond strength at this interface was less than nonopaque composite alone. Despite these findings, the DTS of composite specimens placed with an ethanol lubricant was greater than those placed with a 2-step or 1-step bond lubricant after a 12-week immersion period. However, the specimens placed with ethanol lubricant had a higher variance of fracture pattern, ranging from catastrophic small fragment shatter to uniform fracture at the bonding interface, compared to a more uniform fracture pattern of those placed with bonding agent as an instrument lubricant (see figure 2). It is proposed that due to the opacities within the material and the variability of fracture patterns observed, 
ethanol may be a less suitable and less reliable choice for an instrument lubricant when placing composite restorative materials and as such, would benefit from further investigation.

Furthermore, analysis using two-way ANOVA identified a statistically significant interaction between lubricant and time for DTS. This suggests that whilst both lubricant and time may have a negative impact on the DTS of composite restorative material, both of these variables may interact and thus impact on material properties to a greater extent than if their independent effects were simply combined. The mechanism for this is not fully understood, however it may be a result of differing interactions between lubricant components and their environment, over time.
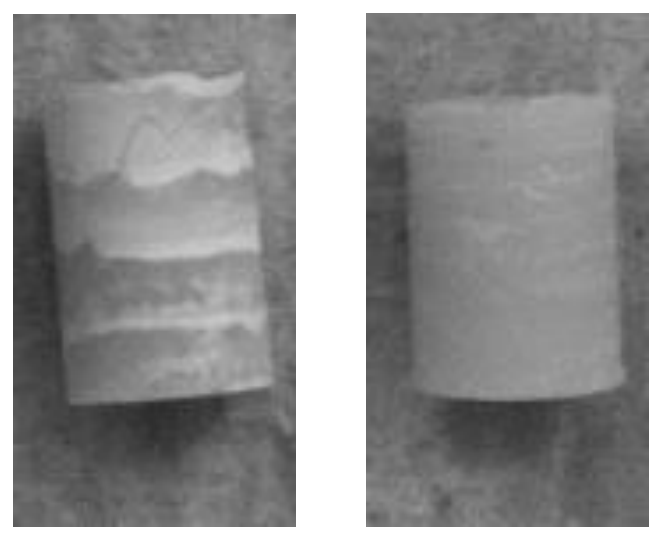

Figure 1: Opaque banding clearly visible in a specimen placed using ethanol as an instrument lubricant (left) when compared to the control specimen placed without any instrument lubricant (right)
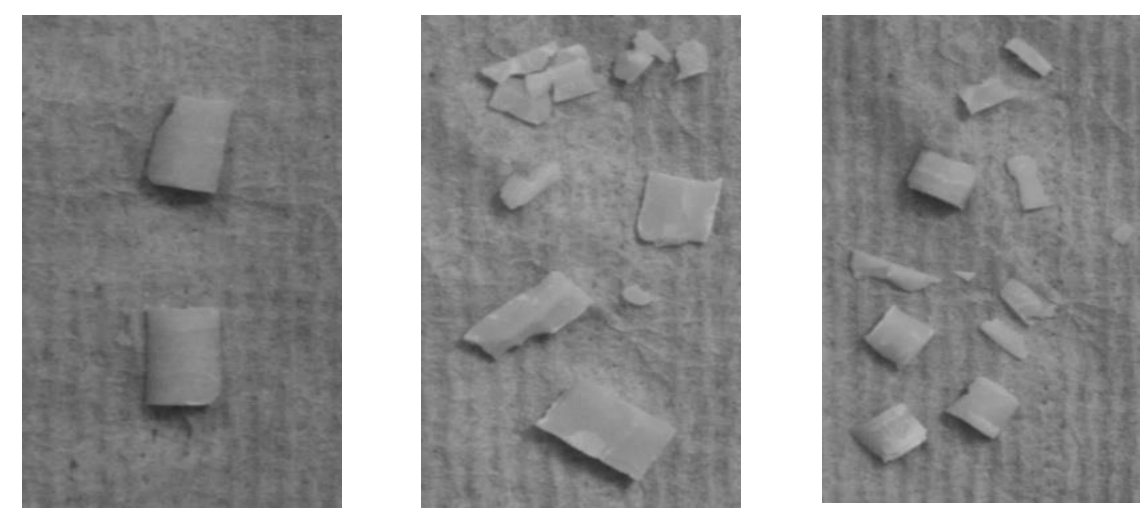

Figure 2: Varying fracture patterns seen between samples placed: with no instrument lubricant (control) (left); with 1-step adhesive system as instrument lubricant (centre) and with ethanol as instrument lubricant (right). Samples in ethanol groups showed significant fracture pattern variability 
The greatest proportion of water uptake occurred in the first week, followed by a gradual decrease between the ' 1 week' and ' 12 week' assessments, similar to reported studies on water sorption $[19,18,33]$. It is clear that the instrument lubricants negatively affected/increased the water uptake of the composite specimens since their mean percentage weight change was significantly higher for the four experimental groups (with lubricant used), compared to the control group. This finding does not support the null hypothesis.

Composite specimens prepared with the three bonding agents as lubricants had a significantly higher water uptake than the ethanol lubricant and control groups. All three bonding agents contained a hydrophilic monomer (HEMA) while the 1-step and 2-step additionally contained water and ethanol. The presence of water in the systems possibly contributed to attracting further water into the resin matrix at the incremental sites. Previous studies have demonstrated that as the volume of unfilled resin increases, the amount of water absorbed into the matrix is increased [18]. Thus, it is possible that the increased hydrophilic HEMA content of the lubricants used was the mechanism responsible for the increased water uptake.

Whilst analysis identified a statistically significant difference for water uptake in different lubricant and time groups, a two-way ANOVA did not identify a statistically significant interaction between these two variables. This suggests that instrument lubricant and time both act independently, and thus in an additive manner, to effect water uptake.

It is important to consider whether the increase in water uptake was one of the mechanisms responsible for the noted decrease in DTS of composite specimens placed with an instrument lubricant compared to control. Indeed, investigation of the possible negative correlation between increased water uptake and decreased strength following instrument lubricant use is an area for further study.

It should be noted that the observed trends apply to the specific materials utilised within the present study. However, as components of many dental composites and adhesive systems are similar within the same generation of products, these trends may be applicable to a wider range of clinically available products. As such, other bonding systems may contain different base components compared to those given in Table 1, for example other adhesive monomers (such as Bis-GMA, UDMA and TEGMA) and solvents/etchants (such as 
polyacylic and itaconic acids) [34]. However, it is anticipated that these will have a similar effect when utilised as an instrument lubricant due to their similar chemical properties. Moreover, although this investigation employed a more clinically relevant protocol for composite specimen construction when compared to previous studies, it must also be acknowledged that the present results were obtained via an invitro study, and therefore cannot be directly extrapolated to the oral cavity and clinical environment. Nonetheless, they can be used to help inform the clinical practice and facilitate evidence based care.

\section{$\underline{\text { 5. Conclusion }}$}

In summary, whilst an instrument lubricant may increase ease of placement for the clinician and alleviate clinical handling challenges, the present study identifies that the use of such lubricants during composite placement leads to both an increase in water uptake and reduction in diametral tensile strength of the composite material. This may subsequently have a negative effect upon the physical and mechanical properties of dental composite and as such, it is promulgated that the use of instrument lubricants should be limited or discontinued. If considered clinically necessary then the use of the bonding solution from a '3-step adhesive system' would appear to be the most suitable choice as an instrument lubricant, as the results described here demonstrate that this has the least deleterious effect upon water uptake and diametral tensile strength of composite materials.

\section{Funding}

This work was supported by a research grant from the Barts and the London SMD Alumni Association.

\section{Conflict of Interest}

None 


\section{References}

[1] F.J.T. Burke, S. McHugh, A.C. Hall, R. Randall, E. Widström, H. Forss, Amalgam and composite use in UK general dental practice in 2001., Br. Dent. J. 194 (2003) 613-618; discussion 609. http://www.nature.com/bdj/journal/v194/n11/abs/4810258a.html.

[2] W.H. Liebenberg, Bonding agent as an instrument lubricant: potential effect on marginal integrity, Pract. Periodontics Aesthetic Dent. 4 (1999).

[3] J. Perdigăo, G. Gomes, Effect of instrument lubricant on the cohesive strength of a hybrid resin composite., Quintessence Int. 37 (2006) 621-5. http://www.ncbi.nlm.nih.gov/pubmed/16922021.

[4] W.J. Dunn, T.C. Strong, Effect of alcohol and unfilled resin in the incremental buildup of resin composite., Quintessence Int. 38 (2007) e20-6. http://www.ncbi.nlm.nih.gov/pubmed/17508071.

[5] J.M. Powers, R.. Craig, Composite Restorative Materials, 11th ed., Restorative Dental Materials, St Louis: Mosby, 2002.

[6] W.D. Sneed, R.A. Draughn, Effect of alcohol on the strength of a composite resin, Oper. Dent. 5 (1980) 47-48.

[7] S.O. Eiriksson, P.N.R. Pereira, E.J. Swift, H.O. Heymann, A. Sigurdsson, Effects of saliva contamination on resin-resin bond strength, Dent. Mater. 20 (2004) 37-44. doi:10.1016/S01095641(03)00066-6.

[8] S.S. Oskoee, E.J. Navimipour, Effect of Composite Resin Contamination with Powdered and Unpowdered Latex Gloves on Its Shear Bond Strength to Bovine Dentin, Oper. Dent. 37 (2012) 492500. doi:10.2341/11-088-L.

[9] M. Fakhri, B. Seraj, M. Shahrabi, P. Motahhary, T. Hooshmand, Effect of salivary contamination on microleakage of resin composites placed with a self-etch adhesive in primary teeth: an in vitro study, Pediatr Dent. 31 (2009) 334-339.

[10] A.H.L. Tjan, J.F. Glancy, Effects of four lubricants used during incremental insertion of two types of visible light-activated composites, J. Prosthet. Dent. 60 (1988) 189-194. doi:10.1016/00223913(88)90314-9.

[11] M. Braden, G.J. Pearson, Analysis of aqueous extract from filled resins, J. Dent. 9 (1981) 141-143.

[12] P.L. Fan, A. Edahl, R.L. Leung, J.W. Stanford, Alternative interpretations of water sorption values of composite resins., J. Dent. Res. 64 (1985) 78-80. http://www.ncbi.nlm.nih.gov/pubmed/3855424. 
[13] T. Hirasawa, S. Hirano, S. Hirabayashi, I. Harashima, M. Aizawa, Initial dimensional change of composites in dry and wet conditions., J. Dent. Res. 62 (1983) 28-31.

http://www.ncbi.nlm.nih.gov/pubmed/6571850.

[14] Y. Momoi, J.F. McCabe, Hygroscopic expansion of resin based composites during 6 months of water storage., Br. Dent. J. 176 (1994) 91-6. http://www.ncbi.nlm.nih.gov/pubmed/7599006.

[15] A.J. Feilzer, a J. de Gee, C.L. Davidson, Relaxation of polymerization contraction shear stress by hygroscopic expansion., J. Dent. Res. 69 (1990) 36-9. doi:10.1177/00220345900690010501.

[16] J.F. McCabe, S. Rusby, Water absorption, dimensional change and radial pressure in resin matrix dental restorative materials, Biomaterials. 25 (2004) 4001-4007. doi:10.1016/j.biomaterials.2003.10.088.

[17] K.J. Söderholm, M. Zigan, M. Ragan, W. Fischlschweiger, M. Bergman, Hydrolytic degradation of dental composites., J. Dent. Res. 63 (1984) 1248-54. doi:10.1177/00220345840630101701.

[18] B. Biradar, S. Biradar, A. Ms, Evaluation of the effect of water on three different light cured composite restorative materials stored in water: An in vitro study, Int. J. Dent. 2012 (2012). doi:10.1155/2012/640942.

[19] I. Sideridou, V. Tserki, G. Papanastasiou, Study of water sorption, solubility and modulus of elasticity of light-cured dimethacrylate-based dental resins, Biomaterials. 24 (2003) 655-665. doi:10.1016/S0142-9612(02)00380-0.

[20] Kerr, Optibond FL Adhesive Manufacturer Safety Data Sheet, (2015) 1-7. https://embed.widencdn.net/download/kavokerr/aegigsatcs/82974_133768.pdf?u=18sth1.

[21] Kerr, Optibond Solo Plus Manufacturer Safety Data Sheet, (2015) 1-8. https://embed.widencdn.net/download/kavokerr/m4axn0ai7y/82379_131385.pdf?u=18sth1.

[22] Kerr, Optibond All In One Manufacturer Safety Data Sheet, (2015) 1-9. https://embed.widencdn.net/download/kavokerr/gby1svcjku/82983_133777.pdf?u=18sth1.

[23] Kerr, Technical Bulletin Kerr Optibond All In One, (2015). https://embed.widencdn.net/download/kavokerr/gby1svcjku/82983_133777.pdf?u=18sth1.

[24] Rueggeberg FA, Caughman WF, Curtis JW, Effect of light intensity and exposure duration on cure of resin composite., Oper. Dent. 19 (1994) 26-32. http://www.ncbi.nlm.nih.gov/pubmed/8183730.

[25] L. Musanje, M. Shu, B.W. Darvell, Water sorption and mechanical behaviour of cosmetic direct 
restorative materials in artificial saliva, Dent. Mater. 17 (2001) 394-401. doi:10.1016/S01095641(00)00097-X.

[26] A. Della Bona, P. Benetti, M. Borba, D. Cecchetti, Flexural and diametral tensile strength of composite resins., Braz. Oral Res. 22 (2008) 84-89.

[27] A. Della Bona, K.J. Anusavice, J.J. Mecholsky, Failure analysis of resin composite bonded to ceramic, Dent. Mater. 19 (2003) 693-699. doi:10.1016/S0109-5641(03)00015-0.

[28] W.M. Palin, G.J.P. Fleming, F.J. Trevor Burke, P.M. Marquis, R.C. Randall, The reliability in flexural strength testing of a novel dental composite, J. Dent. 31 (2003) 549-557. doi:10.1016/S03005712(03)00110-6.

[29] I.B. Larsen, E.C. Munksgaard, Effect of human saliva on surface degradation of composite resins., Scand. J. Dent. Res. 99 (1991) 254-61. doi:10.1111/j.1600-0722.1991.tb01893.x.

[30] J. De Munck, B. Van Meerbeek, Y. Yoshida, S. Inoue, M. Vargas, K. Suzuki, P. Lambrechts, G. Vanherle, Four-year water degradation of total-etch adhesives bonded to denim, Biomed. Mater. Eng. 82 (2003) 136-140. http://content.iospress.com/articles/bio-medical-materials-and-engineering/bme52-05.

[31] a U. Yap, S.H. Tan, S.S. Wee, C.W. Lee, E.L. Lim, K.Y. Zeng, Chemical degradation of composite restoratives., J. Oral Rehabil. 28 (2001) 1015-1021. doi:10.1111/j.1365-2842.2001.00760.x.

[32] R.W. Penn, R.G. Craig, J.A. Tesk, Diametral tensile strength and dental composites, Dent. Mater. 3 (1987) 46-48. doi:10.1016/S0109-5641(87)80062-3.

[33] A.M. Diaz-Arnold, M.A. Arnold, V.D. Williams, Measurement of water sorption by resin composite adhesives with near-infrared spectroscopy, J Dent Res. 71 (1992) 438-442.

http://www.ncbi.nlm.nih.gov/entrez/query.fcgi?cmd=Retrieve \&db=PubMed\&dopt=Citation\&list_uid $\mathrm{s}=1573074$.

[34] 3M ESPE, Adper Easy Bond Vial Manufacturer Safety Data Sheet, (2015) 1-12. http://multimedia.3m.com/mws/mediawebserver?mwsId=SSSSSuUn_zu8100xMxmv58_Bnv70k17zH vu91xtD7SSSSSS--. 